\title{
ARTIGO \\ O Cameralismo e os fundamentos da Ciência do Estado nos escritos de Seckendorf, Justi e Sonnenfels
}

Flávio Oliveira ${ }^{1}$

Como citar este artigo: OLIVEIRA, Flávio. O Cameralismo e os fundamentos da Ciência do Estado nos escritos de Seckendorf, Justi e Sonnenfels. Revista de Ciências do Estado. Belo Horizonte: v. 6, n. 1, e25602. ISSN: 2525-8036.

Resumo: $\mathrm{O}$ artigo evidencia aspectos do panorama político no qual se desenvolveu o Cameralismo a fim de avaliar as contribuições de Seckendorff, Justi e Sonnenfels à institucionalização da Ciência do Estado (Staatswissenschaft). Baseando-se em fontes primárias, bem como nas obras de renomados estudiosos do assunto, a investigação constata convergências entre a doutrina cameralista e o pensamento econômico em voga à época. Verifica-se que, embora tenha sido concebido para assessorar o governo monárquico quanto à solução de questões práticas de administração pública, política econômica e finanças, o Cameralismo produziu efeitos de longo prazo, constituindo os alicerces sobre os quais se assentam, de um lado, a Nationalökonomie, e de outro a perspectiva orgânica inerente à organização estatal alemã.

Palavras-chave: Cameralismo; Ciência do Estado; Seckendorff; Justi; Sonnenfels.

Recebido em 05.09.2020

Aprovado em 08.04.2021

Publicado em .04.2021

\section{INTRODUÇÃO}

As guerras religiosas e dinásticas que se sucederam ao longo dos séculos XVI e XVIII não apenas dividiram a cristandade europeia, desencadeando o processo de fragmentação política do Sacro Império Germânico, mas também tornaram imprescindíveis a reorganização de todo um aparato administrativo. Para fazer frente às grandes potências, os principados alemães viram-se diante da necessidade de suprimir resquícios do feudalismo, começando por

1 Pós-doutorado em História pelos Programa de Pós-Graduação em História Social das Relações Políticas da Universidade Federal do Espírito Santo (UFES). Ocupa-se de pesquisas nas áreas de História do Pensamento Econômico, História Econômica, História Política e História da Filosofia. 
reforçar junto aos seus quadros a aplicação de princípios racionais como probidade, diligência, obediência hierárquica etc. Isso refletia, na verdade, a percepção de que o ato de governar não se limita ao exercício do poder e sua conservação, mas urge também o desenvolvimento de atitudes que promovam centralização política, supressão de práticas antiquadas, enriquecimento do Estado e bem-estar dos súditos (Untertanen).

Ante a crescente ameaça da França, Inglaterra e Escandinávia, manifestou-se entre os príncipes alemães o desígnio de fundar um Estado moderno. A fim de desenvolver as potencialidades de seus domínios, assegurando fluxo constante de receitas fiscais, era mister que o soberano tivesse à disposição um conhecimento fidedigno acerca das condições materiais e geográficas do território, bem como da situação demográfica, social e política. Nesse sentido, para suprir-se de funcionários competentes, cátedras de Ciências Camerais (Kameralwissenschaften) foram fundadas. Com efeito, o Cameralismo expressa uma intenção concreta de tornar eficiente a administração e o controle fiscal, num período em que o desenvolvimento da economia financeira estatal e a obtenção de fundos públicos eram tarefas de suma relevância. A esse respeito, cumpre frisar que embora muitos cameralistas tenham se ocupado da docência, eles eram essencialmente administradores e estadistas que compunham as câmaras de conselheiros governamentais, de sorte que sua principal incumbência consistia em fornecer ao soberano informações confiáveis que o orientassem no que concerne à cabal gestão fiscal e à profícua regulação econômica (JACKSON, 2005, p. 1294-1297; LÜTGE, 1966, p. 321).

Outra questão central por trás da política cameralista relaciona-se ao entendimento de que a riqueza nacional se localiza na capacidade produtiva dos indivíduos, resultando disso a exigência de investimentos em educação, infraestrutura e avanço tecnológico. Em outros termos, a prosperidade de um Estado depende da adoção de medidas que promovam a melhoria material e espiritual dos cidadãos, tema de grande importância e aplicação na atualidade. Com efeito, para entender com relativa profundidade as ideias cameralistas, além de inseri-las no contexto maior do pensamento político-econômico da época, recorreu-se aos escritos de alguns de seus principais representantes, isto é, Veit Ludwig von Seckendorff (1626-1692), Johann Heinrich Gottlob von Justi (1717-1771) e Joseph von Sonnenfels (17331817), considerando-se basicamente três recortes temporais, a saber, o período a suceder à Guerra dos Trinta Anos (1618-1648), o lapso correspondente ao Século das Luzes e o intervalo entre a Revolução Francesa e as guerras napoleônicas. Salientam-se de suas elucubrações diferentes pontos de vista acerca da Ciência da Polícia (Polizeiwissenschaf), Ciência do Comércio (Commercienwissenschaft) e Ciência das Finanças 
(Finanzwissenschaft), as quais, em tese geral, ocupar-se-iam de tornar os cidadãos mais produtivos e com isso aumentar a riqueza e a prosperidade do Estado, mediante procedimento governamental sistematizado, articulando economia, política e gestão de homens e recursos escassos.

O pressuposto fundamental que norteia este estudo baseia-se no fato de que nenhum texto fala com voz única, ou seja, nenhum autor extrai suas ideias de uma intuição pura $a$ priori, anterior a qualquer experiência. Ao contrário, seus escritos respondem às grandes questões de seu tempo, o que impõe de um lado fazer um exame minucioso das particularidades teóricas da obra, e de outro buscar entendê-la à luz do contexto em que foi concebida. Para tanto, o procedimento metodológico aqui empregado respalda-se na pesquisa qualitativa de cunho documental, a qual se caracteriza pelo esforço de compreender materiais escritos como, por exemplo, jornais, revistas, obras literárias e científicas, cartas etc., a partir do contexto histórico em que surgiu e do qual é parte, buscando-se com isso elaborar novas e/ou complementares interpretações para os fenômenos estudados, mediante a técnica de análise de seu conteúdo, de modo que se vislumbre evidências que propiciem a inferência de conhecimentos relativos às condições de produção e recepção de suas mensagens (GODOY, 1995, p. 22-23).

\section{PANORAMA HISTÓRICO DO SURGIMENTO DO CAMERALISMO}

No Sacro Império Germânico tendências políticas e econômicas tradicionais tiveram de ser modificadas para se adequar às novas exigências decorrentes da necessidade de reparação dos territórios devastados pela Guerra dos Trinta Anos (1618-1648). Estima-se que após o conflito, em alguns lugares, a população foi reduzida a menos da metade. Por isso, lançar luz sobre a questão atinente à restauração das estruturas política e econômica desses domínios significa entender o papel da ciência administrativa na superação de crises provocadas por guerras, como as que assolavam os territórios germânicos nos séculos XVII e XVIII. Nesse sentido, os homens incumbidos de elaborar uma teoria da gestão pública tiveram efetivamente que responder à seguinte questão: que programa deve um governo sábio adotar a fim de ser suficientemente abastecido com dinheiro, e, assim, ser capaz de cumprir os deveres do Estado em suas várias ordens de importância? (KRAUS, 2011, 106; SMALL, 2001 [1909], p. 21-22).

$\mathrm{Na}$ ausência de um Estado Alemão unificado, os príncipes viram-se obrigados a reorganizar as atividades econômicas de sua gleba tendo em vista um mundo dominado cada 
vez mais pela competição violenta entre impérios globais. Tal circunstância criou as condições propícias à introdução do Estado de Polícia (Staatspolizei), isto é, um arranjo institucional baseado numa relação de dependência mútua entre o príncipe e súditos, em que estes estavam comprometidos a obedecer, enquanto aquele lhes proporcionasse dignidade e bem-estar. ${ }^{2}$ Para desempenhar cabalmente suas funções, o príncipe restabeleceu uma antiga instituição medieval, a Câmara (Der Kammer), expressão que provém da tradução latina da palavra grega $K \alpha \mu \alpha ́ \rho \alpha$, empregada inicialmente para designar o recinto privado do príncipe, e, em seguida, por extensão, o locus de sua administração ${ }^{3}$ (REINERT, 2011, p. 40-47; SCHUMPETER, 2006, p. 142-155; SMALL, 2001 [1909], p. 3; GUERRERO, 1985, p. 16).

O Cameralismo tornou-se realidade institucional graças ao esforço intelectual de funcionários públicos, consultores administrativos e professores universitários para conhecer, instrumentalizar e fortalecer o Estado ante os desafios resultantes das novas configurações políticas inerentes à consolidação das monarquias modernas. A esse respeito, merece destaque a necessidade de dar resposta à crescente demanda por instrução da parte de jovens nobres que se preparavam para o serviço público de carreira, ou de funcionários mais antigos que desejavam melhorar a gestão administrativa. No decorrer do século XVIII, cátedras começaram a ser ofertadas para o ensino daquilo que foi descrito como Ciência Cameral ou Ciência do Estado (Staatswissenschaft), mas que pode ser caracterizado com mais precisão como Princípios de Administração e Política Econômica ${ }^{4}$ (SCHUMPETER, 2006, p. 155).

\footnotetext{
2 Tal como a palavra Oıкovouía, o vocábulo Polizei (polícia) tem sua origem em Aristóteles. De fato, este termo

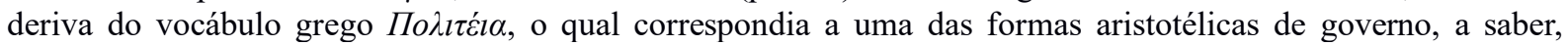
aquela responsável pela regência de muitos indivíduos. O epíteto Polizeiwissenschaft apareceu nos territórios germânicos no século XV, a princípio, referindo-se à organização eficiente da administração doméstica, já que os assuntos militares, bem como as questões externas ao reino eram considerados prerrogativas exclusivas do príncipe. Com o tempo, seu raio de atuação foi-se ampliando, de modo a abarcar não apenas a ideia de bemestar, mas também de prosperidade tanto para o Estado, quanto para os cidadãos (LINDENFELD, 1997, p. 1820; HEGEL, 1973, p. 310).

3 A Kammer era uma instituição política deliberativa em forma de colegiado, cujos membros, os cameralistas, ponderavam sobre questões concernentes aos negócios públicos, visando de um lado atender às necessidades do Estado, e de outro desenvolver o potencial produtivo da comunidade. Sua composição era poliárquica e sua forma organizativa baseava-se no acordo consensual (KRAUS, 1985, p. 17). Com o tempo, além dos impostos, as autoridades camerais adquiriram gradualmente a gestão das outras duas principais fontes de renda do Estado, ou seja, as terras principescas (Domaenen) e concessões governamentais (Regalien), as quais consistiam (i) no controle da mineração e salinas; (ii) alfândegas e portagens; (iii) outorga de títulos e monopólios; (iv) serviço postal etc. A extensão dos poderes da Kammer nestas áreas marcou assim um avanço na institucionalização das rendas públicas e privadas dos príncipes (TRIBE, 2004, p. 9; LINDENFELD, 1997, p. 15).

4 A primeira cátedra de Ciência Cameral foi instituída na Prússia em 1727. Por meio de um decreto de 24 de julho do mesmo ano, Frederico Guilherme I nomeou Simon Peter Gasser (1676-1745) para lecionar a disciplina Oeconomie, Polizey und Kammersachen, na Universidade de Halle, com o propósito de que a juventude prussiana pudesse adquirir boa formação antes que fossem empregados no serviço público. Nota-se que o próprio rei foi a Halle para ministrar a palestra inaugural do curso de Kameralwissenschaften, onde explicitou sua insatisfação com o fato dos estudantes de Direito serem ignorantes quanto aos assuntos de Economia e Finanças. A segunda instituição a levar adiante o ensino do Cameralismo, também em 1727, foi a Universidade
} 
Em linhas gerais, pode-se dizer que o cameralismo atravessou quatro etapas de desenvolvimento: (i) a fase original, que vai do início do século XVI a meados do século XVII, período caracterizado pelo esforço para solapar os resquícios do feudalismo; (ii) a fase sistemática (1656-1727), correspondendo ao lapso concernente ao ano de publicação da obra de Seckendorff e o ano da fundação da cátedra de Ciências Camerais. Segue-se (iii) a fase acadêmica, na qual é estabelecida o curso Kameral-Oekonomie und Polizeywissenschaft, nas Universidades de Halle e Frankfurt an der Oder, isto é, quando as Ciências Camerais se tornam uma disciplina universitária definitivamente; e por fim (iv) a fase científica (17551848), em que se concebe e realiza a técnica cameralista por meio da contribuição de Johann Heinrich Gottlob von Justi. Essa fase se conclui em meados do século XIX, quando ainda se ensinava a obra de Joseph von Sonnenfels. ${ }^{5}$

Ao contrário do que comumente se afirma acerca do Cameralismo, considerando-o uma mera versão alemã do mercantilismo, ele representava uma espécie de "tecnologia administrativa", cujas técnicas e teorias foram desenvolvidas e sistematizadas entre meados do Século XVI e finais do século XVIII, em que Estado foi concebido como entidade coletiva, orgânica e unitária, ao mesmo tempo em que se caracteriza como um tipo de reflexão econômica e um programa de ação prática que refletia na verdade o crescente intercâmbio cultural que veio se intensificando na Europa desde o invento da imprensa.6 Um caso emblemático disso é o do escocês James Steuart (1712-1780), conhecedor do Cameralismo e do mundo germânico, e que influenciou sobremodo a filosofia política de George W. F. Hegel (1770-1831). Por sua vez, Justi e Sonnenfels foram fortemente influenciados, respectivamente, por Melon e por Forbonnais. Por fim, não se deve esquecer a grande difusão

de Frankfurt an der Oder, onde o historiador Justus C. Dithmar (1676-1745) foi nomeado professor de KameralOekonomie und Polizeiwissenschaft (TRIBE, 2004, p. 9; 1988, p. 42-43; LINDENFELD, 1997, p. 15).

5 Há unanimidade entre os estudiosos do Cameralismo sobre a influência original exercida sobre ele por Pufendorf, Thomasius e Wolff. Esses eruditos legaram-lhe o importante conceito de "felicidade" (Glückseligkeit), tão frequente e estrategicamente utilizado pelos autores cameralistas. Pufendorf, por exemplo, contribui ademais com as noções de "conveniência" e "dever", a primeira tão próxima à ideia de felicidade e a segunda tão importante à definição de responsabilidade social. Wolff, por seu turno, brindou o conceito de "bemestar" (Wohlfahrt), o qual tem sua origem no direito natural dos súditos. Além disso, nele se encontram os rudimentos teoria do estado policial em que reside a demanda comum de seguridade e ordem (GUERRERO, 1986, p. 82-83).

6 Em 1754 e 1766, apareceram duas traduções alemãs dos escritos econômicos de David Hume (1711-1776), sob o título: Vermischte Schriften über die Handlung, die Manufacturen und die andern Quelle des Reichthums und der Macht eines Staats (Escritos mistos sobre o comércio, as manufaturas e as outras fontes de riqueza e poder de um Estado) (Hamburg, 1752; Leipzig, 1766). Em 1755, os Elémens du Commerce, de Forbonnais, foram traduzidos como Der Vernuftige Kaufmann (1755-1767). Posteriormente, as Lezioni di Commercio ossia de Economia Civile, de Antonio Genovesi, foram publicadas em três edições como Grundsätze der Bürgerlichen Ökonomie, 2 Bände (Leipzig, 1765; 1769; 1776). Do mesmo modo, a obra Meditazione sulla Economia Politica, de P. Verri, foi traduzida em 1785 como Betrachtungen über die Staatswirthschaft. Finalmente, os Essay (1767) e os Institutes (1769) de Adam Ferguson também foram traduzidos para alemão nesse período (TRIBE, 1988, p. $135)$. 
do pensamento de Genevan Jacques Necker em toda a Europa continental e especificamente na Alemanha (Deutschland) ${ }^{7}$ (BILHIM; RAMOS; PEREIRA, 2015, p. 111-116; LLUCH, 1996, p. 163).

Decerto, nota-se relativa aproximação doutrinária entre o chamado mercantilismo avançado, caracterizado pelo entendimento de que um estado moderno deveria se concentrar no desenvolvimento da indústria por meio da expansão da demanda por luxo, gastos públicos, liberalização interna, estabelecimento de planos e metas, proteção externa etc., e o Cameralismo, o que torna patente a natureza cosmopolítica dos grandes debates da época. A variação observável entre cameralistas, colberistas e mercantilistas pode, em certa medida, ser considerada a consequência inevitável da adaptação das ideias econômicas às estruturas políticas pré-existentes. Um elemento distintivo do Cameralismo, contudo, localiza-se na convicção de que seus princípios podem ser ensinados por meio da cátedra, constituindo uma poderosa via pedagógica para que os funcionários públicos conheçam os melhores meios de promover a grandeza do Estado e o bem-estar comum. (CUNHA, 2013, p. 2; BELL, 1961, p. 104; REINERT, 2005, p. 271).

\section{SECKENDORFF E AS BASE ECONÔMICAS DO ESTADO DE BEM-ESTAR}

Veit Ludwig von Seckendorff nasceu no seio de uma antiga família aristocrática a 20 de dezembro de 1626, em Herzogenaurach, Bavária. Sua formação inicial constituiu-se no famoso Gymnasium Illustre na cidade de Gotha, apesar de o período em que viveu em Thüringen ter sido marcado pela penúria e violência provocadas pela Guerra dos Trinta Anos. Como seu pai havia lutado ao lado do duque Ernst des Frommen (1601-1675), o jovem Seckendorff auferiu-lhes favores, podendo frequentar a prestigiosa Universidade de Estraburgo, na qual aprofundou seus estudos em Filosofia, História, Direito e Teologia. Após retornar a Gotha, foi incorporado à vida pública, a princípio, ocupando-se da direção da Biblioteca Ducal, em que se incumbia de sumarizar e explicar ao duque as principais obras contemporâneas. Em seguida, atuou como Hofjunker (1646), Kammerjunker (1648), Justizrat und Mitglied der Ratsstube (Conselheiro judicial e membro da Câmara de Conselho, 1655), Geheimer Hof- und Kammerrat (Conselheiro do Tribunal Secreto e da Câmara), assumindo,

7 Como já discutido no âmbito da história das ideias, se certo autor poderia ter sido influenciado intelectualmente por algumas fontes específicas, a transferência de ideias é definida como o movimento intencional de discursos e conceitos acadêmicos entre duas tradições, destacando-se disso basicamente três processos, a saber, a mediação, seleção e recepção, bem como as instituições que favorecem essa transmissão (ROSSER, 2010, p. 548). 
por fim, o honroso posto de Direktor des Geheimen Rates (Diretor do Conselho Secreto) ${ }^{8}$ (KLINGER, 2002, p. 141; REINERT, 2005, p. 276).

Já no século XVIII, era aceito que Seckendorff fundou os alicerces das Ciências Camerais por meio de suas Additiones oder Zugaben und Erleuterungen zu dem Tractat des Teutscher Fürsten-Staats (Adendo ou informações e notas ao Tratado do Estado Principesco Alemão, 1665). Sua primeira obra, Teutscher Fürsten-Staat (Estado Principesco Alemão, 1656), divide-se basicamente em três partes: (i) um tratado que descreve os meios para mapear plenamente as condições materiais e geográficas de um território, com foco em detectar e aproveitar da maneira mais adequada os recursos naturais; (ii) uma extensa seção sobre a estrutura social e organizacional do governo, tanto do ponto de vista espiritual quanto material; por fim, segue-se (iii) uma abrangente discussão sobre finanças públicas e o modo mais eficiente de garantir um fluxo de receitas fiscais. ${ }^{9}$ Por outro lado, os Additiones resultam de um processo de amadurecimento e crítica empírica extraídos da observação da florescente economia holandesa, quando de suas viagens com o duque Ernst I. Nessa obra, Seckendorff trata essencialmente de revelar os efeitos perniciosos da dependência econômica estrangeira10 (SECKENDORFF, 1665, p. 188-189; GUERRERO, 1985, p. 94; REINERT, 2005, p. 280).

Seckendorff é enfático ao afimar que apenas poucas pessoas lucram com a importação de mercadorias. Apesar de alguns comerciantes se beneficiarem de tal intercâmbio, muito pouco auferem o Estado e as pessoas comuns, visto que, nesse caso, a porção mais substancial daquilo de que se necessita para o bem-estar localiza-se no exterior, o que explica não apenas

8 Omar Guerrero insere Seckendorff, bem como Melchor von Osse (1506-1556) e Georg Obrecht, no seleto grupo de conselheiros de príncipes que mais contribuíram para consolidação do Cameralismo. Seu aporte se fez necessário especialmente no período em que as demarcações entre os principados eram tão imprecisas que os problemas inerentes à delimitação de soberanias entre eles, assim como em relação ao Sacro Imperador, tornavam imprescindíveis a colaboração de assessores políticos gabaritados (GUERRRERO, 1985, p. 84).

9 Seckendorff preconiza que no início de qualquer trabalho administrativo sistemático, deve-se ter como ponto de partida a realização de um inventário abrangente de todas as circunstâncias regionais, focalizando tanto os recursos disponíveis, quanto suas deficiências. No que concerne ao poder político, não obstante a complexidade de questões como probidade da gestão físcal; o estabelecimento das condições propícias à produção agrícola; a regulamentação dos pesos e medidas; as finanças etc., deve trabalhar o príncipe, enquanto chefe da administração, tal como todas as demais autoridades, para a glória de Deus, de sorte que sua conduta seja um modelo para os súditos (MACK, 1997, p. 8).

10 Em Teuscher Fürsten-Staat se verifica estreita relação com o pensamento político da época, com destaque para Los Espejos de Príncipes e a doutrina da Raison d'État. Nessa obra, encontra-se forte apelo moral e religioso como elemento de controle dos atos políticos dos príncipes, razão pela qual Seckendorff é reconhecido como um dos arautos da modalidade alemã dos Consejos de Príncipes. Seus escritos integram, no entanto, outras matérias exclusivas do pensamento cameral, reflexo de seu diagnóstico das condições políticas dos Estados Alemães, como o melhoramento da educação dos jovens; a promoção das ocupações produtivas; a proteção do comércio interno; a regulação dos preços, pesos e medidas; a administração eficiente dos impostos etc. Estas questões constituíram, como se verá adiante, a base das preocupações teóricas cameralistas subsequentes (REINERT, 2005, p. 226; GUERRERO, 1986, p. 95-96). 
a elevação do custo de vida, mas também a migração, que em geral drena para outros países justamente a parte mais produtiva do capital humano nacional. Em sua visão, na falta de um setor manufatureiro livre e pujante, um país não seria capaz de sustentar de forma duradoura uma população crescente e, portanto, seus cidadãos inevitavelmente correriam para países estrangeiros, onde vigoram melhores condições de vida. Assim, Seckendorff identificava nessa fuga de mão de obra um círculo vicioso, pois à medida que se reduzia a força de trabalho, isso mantinha os principados alemães em um estado de dependência das importações estrangeiras (SECKENDORFF, 1665, p. 191; REINERT, 2005, p. 280).

É provável que, na Holanda, Seckendorff tenha compreendido a importância crucial das manufaturas para, de um lado, reverter a situação de pobreza e declínio demográfico que debilitavam diversos principados alemães, e de outro desenvolver a capacidade produtiva doméstica e articular todas as atividades econômicas, criando riqueza e empregos no processo. Nesse sentido, ele figura também entre os primeiros a destacar os efeitos deletérios da exportação de matérias primas, e importação de manufaturados. Em seu entendimento, a subordinação econômica pode ser apontada como uma das principais causas do desemprego e da pobreza. ${ }^{11}$ Seckendorff preconiza, assim, medidas destinadas a desenvolver as forças produtivas dos súditos para escapar da excessiva e debilitante submissão às potências estrangeiras. De fato, sua principal recomendação é justamente a substituição de importações como forma de suprir as necessidades econômicas domésticas.12 Em outros termos, ele acreditava que um país caracterizado apenas por uma agricultura de subsistência jamais poderia prosperar. Seu modelo de Estado contempla, assim, um príncipe esclarecido guiando a sociedade civil composta por artesãos urbanos que trabalham em sintonia com o homem da terra (SECKENDORFF, 1665, p. 188-191; REINERT, 2005, p. 278).

Para desenvolver as manufaturas, pensava Seckendorff, era preciso libertar os artesãos dos grilhões das guildas e corporações de ofício. Isso atrairia mais trabalhadores, criaria

11 Esse argumento será posteriormente desenvolvido por diversos autores em defesa da indústria nascente. David Hume (1711-1776), por exemplo, em seu ensaio Of the Balance of Trade (Sobre a Balança Comercial, 1752) afirma que impostos moderados e graduais não apenas incentivam a indústria nativa, mas também podem aumentar a diligência e probidade dos trabalhadores (HUME, 1983 [1752], p. 225). Friedrich List (1789-1846), por sua vez, em seu Sistema Nacional de Economia Política (1841) sugere que o comércio internacional é muito imperfeito, já que pode ser interrompido a qualquer momento por guerras, regulamentos políticos, crises comerciais etc. Por isso, é importante que, antes de tudo, um país desenvolva sua própria indústria (LIST, 1983 [1841], p. 113).

12 Seckendorff ainda apregoava como medidas de política econômica o incentivo e a proteção da produção local mediante a industrialização de matérias-primas autóctones; a eliminação das guildas; o fomento de novas atividades econômicas para incrementar a divisão do trabalho; o arrendamento das terras públicas para superar o problema da crescente pressão populacional; o estímulo ao aperfeiçoamento das forças produtivas por meio de uma moderna política educacional etc. No tocante à economia política, além da supressão das tarifas aduaneiras internas, ele pugna por um sistema de tributação baseado no imposto especial de consumo (REINERT, 2011, p. 48; 2005, p. 228; SMALL, 2001 [1909], p. 68; LINDENFELD, 1997, p. 14-15; GUERRERO, 1986, p. 94). 
demanda por novos negócios para suprir suas necessidades e, assim, gerar-se-ia um círculo produtivo de oferta e demanda crescentes, de sorte que um comércio retroalimenta o outro em um sistema que hoje se denomina causas cumulativas. Eximir as manufaturas de restrições, bem como liberar os preços dos bens domésticos, revigorariam toda a economia, trazendo os preços aos seus "níveis justos". De fato, como ressalta Erik S. Reinert, é difícil encontrar um economista do século XVII, seja colbertista, cameralista ou mercantilista, que não defendesse a necessidade da industrialização por substituição de importações como meio necessário de desenvolvimento econômico (SECKENDORFF, 1665, p. 189-190; REINERT, 2005, p. 281283).

Seu objetivo era, portanto, criar condições favoráveis à superação do retardo técnico dos principados alemães, tendo em vista a competição desigual com Escandinávia, Inglaterra, França e Países Baixos (SCHUMPETER, 2006, p. 164; REINERT, 2005, p. 222). Como sumarizado por Albion Small, ao comentar as propostas econômicas de Seckendorff:

\begin{abstract}
Daí então segue um esboço similar, sob cinco títulos, de medidas a serem empregadas na obtenção das maiores vantagens dos excedentes de produção de um país, a saber: (1) levantamento dos principais produtos domésticos, adotando-se políticas para o seu encorajamento; (2) a influência do governo deve ser utilizada para manter a população zelosa na continuidade de tais ocupações vantajosas; (3) oferecimento de estímulos aos negociantes de outros países na aquisição desses bens; (4) regulação cuidadosa dos indivíduos desejosos de conduzir comércio exterior com esses bens; (5) proteção dos consumidores domésticos contra vários tipos de fraudes (SMALL, 2001 [1909], p. 82-83).
\end{abstract}

No que concerne ao poder político, Seckendorff concebe o Estado de um ponto de vista holístico, isto é, como uma unidade orgânica, tendo no ápice o príncipe, ainda que este não usufrua prerrogativas absolutistas, mas restrinja a finalidade de seu governo a promover o bem comum, marca indelével da concepção alemã da economia pelos próximos trezentos anos. De fato, em suas obras já se vislumbram os rudimentos dos primeiros ideais relacionados ao Estado de Bem-Estar (Wohlfahrtsstaat), ao se chamar a atenção para a responsabilidade do governo no que concerne à ajuda aos necessitados. Com ele, a Ciência da Polícia (Polizeywissenschaft) aufere os contornos próprios do Cameralismo, voltando-se para o estudo da manutenção e melhoria da população, bem como seu enriquecimento por meio da promoção de suas potencialidades para o trabalho, mediante o uso da administração e da gestão para alcançar tal finalidade. ${ }^{13}$ (SECKENDORFF, 1754, p. 6-7; KRAUS, 2011, p. 107; REINERT, 2005, p. 226-227; SMALL, 2001 [1909], p. 60-61).

13 Nota-se que a expressão Policey (polícia) ainda no início da modernidade já significava administração. Melchor von Osse (1506-1557), por exemplo, asseverava que cabe à polícia não apenas generalizar os benefícios da educação e promover a expansão do aprendizado nas artes mecânicas, mas também eliminar os abusos da 
Por isso, a criação de infraetrutura e o incentivo ao trabalho constituem premissas dos esforços da administração pública. Igualmente, Seckendorff afirmava ser incumbência do Estado regular o comércio por meio de intervenções sobre o mercado a fim de manter preços e salários justos. Escrevendo em um contexto altamente competitivo do capitalismo em sua fase comercial, ele argumenta existirem dois pilares seguros a sustentar o governo: o primeiro, um exército permanente e, o segundo, um apreciável estoque de capital. Ainda que homens em armas possam preservar a paz e a justiça, continua ele, sem dinheiro nada pode ser feito. A principal preocupação do governante responsável, portanto, deveria ser arrecadar dinheiro suficiente para assegurar seu poder, e a única maneira definitiva de se garantir o financiamento adequado de tais pilares se resume à conjugação do interesse do governo com o de seus súditos (TRIBE, 2006, p. 528; LINDENFELD, 1997, p. 12; MACK, 1997, p. 9).

\section{JUSTI E A FUNÇÃO PRECÍPUA DO ESTADO}

Em sua forma original, a cameralística consistia na formulação de propostas práticas, visando tornar eficientes a administração, a arrecadação e a utilização das receitas públicas pelos príncipes, não se constituindo, portanto, uma disciplina segundo os padrões científicos. No século XVIII, no entanto, sucedeu-se notável esforço para oficializar o ensino universitário das Ciências Camerais, embora a princípio algumas inconsistências dificultassem sobremodo sua institucionalização. A obra Einleitung in die Oekonomische Policei-und Cameral-Wissenschaften (Introdução à Política Econômica e Ciências Camerais, 1755) de Justus C. Dithmar é um exemplo emblemático disso. Não obstante a inovação de seu aporte analítico, o manuscrito alberga também imprecisões conceituais e metodológicas. A categoria Glückseligkeit (felicidade), citando um caso representativo, não é adequadamente analisada, nem filosoficamente fundamentada. Além disso, termos econômicos centrais, como custos (Kosten), não são rigorosamente definidos (BUSCH, 2010, p. 1).

Decerto, o Cameralismo somente atingiu robustez teórica nas obras de Johann Heinrich Gottlob von Justi, que lhe conferiu entendimento cada vez mais econômico dos fundamentos da vida política e social, sendo por isso reconhecido como um dos precursores da Economia Política na Alemanha. Embora tenha sido autor de um total de sessenta e sete livros, compreendendo filosofia, literatura, ciência da natureza, geologia etc., seu grande mérito foi ter logrado dividir habilmente as Ciências Camerais em Ciências Econômicas, Ciência Política e Ciência das Finanças, questão que nenhum dos pensadores anteriores havia

nobreza e dos oficiais do reino, corrigir os sistemas penitenciários, evitar o aumento do custo dos bens de consumo básicos etc. (NEU, 2009, p. 90; GUERRERO, 1985, p. 84). 
resolvido plenamente. Atento aos problemas do seu tempo, seus escritos evidenciam os enormes obstáculos a obliterar o desenvolvimento econômico da Alemanha, refletindo outrossim sua experiência como burocrata, professor de economia e ciência política, consultor econômico, gerente de investimentos do governo, minerador etc. (REINERT, 2019, p. 204205; NOKKALA, 2019, p. 5; ADAM, 2006, p. 11).

Nascido em 25 de dezembro de 1720, em Brücken an der Helme, na Turíngia, Justi estudou Direito, Ciências Camerais e Ciência Mineral, em Wittenberg, Jena e Leipzig, respectivamente, durante o aufgeklärter Absolutismus (despotismo esclarecido). Após posicionar-se em favor de Isaac Newton (1643-1727) quanto à polêmica envolvendo a teoria das mônadas de Gottfried W. Leibniz (1646-1716), despertou Justi o descontentamento de eminentes intelectuais alemães, como Christian Wolff (1679-1754). Posteriormente ele migrou para Áustria, onde veio a ocupar a cátedra de Eloquentia Germanica no Collegium Theresianum, a prestigiosa Ritterakademie, fundada em 1746, durante a regência de Maria Theresa (1740-1780), para formar os quadros do oficialato e da burocracia austríaca. Embora sua palestra inaugural, Anweisung zu einer guten Deutschen Schreibart (Instruções para um bom estilo de escrita alemã, 1755), tenha sido concebida para reformar a linguagem jurídica, ela trata ademais de um tema assaz diferente, a saber, a conexão entre o florescimento das ciências e os meios para tornar um Estado forte e feliz, contendo um plano detalhado para o ensino das Ciências Camerais (NOKKALA, 2019, p. 1; REINERT, 2019, p. 208-209; SMALL, 1909, p. 240).

Em 1752, Justi obtém o cargo de Professor de Praxis im Cameral-, Commercial- und Bergwesen (Prática Cameral, Comércio e Mineração). Desde então, ainda que paulatinamente, as Ciências Camerais avançaram rumo à análise cada vez mais objetiva do poder político, evidenciando uma transição da arte de governar à Ciência do Estado (Staatswissenschaft), o que significava na prática tomar certo distanciamento em relação à pessoa do soberano (NOKKALA, 2019, p. 13). Em conexão com esse professorado, Justi foi instruído pelo conde Friedrich W. von Haugwitz, o potente ministro das reformas ilustradas em andamento na Áustria, a oferecer uma disciplina intitulada Collegium Oeconomicoprovinciale, a qual se ocuparia de finanças, comércio, tributação, agricultura e indústria. Assim, no mesmo ano, foi apresentado seu plano de ensino intitulado Kurzer Systematischer Grundriss aller Ökonomischen und Kameralwissenschaften (Esboço Sistemático do Curso de toda Ciência Econômica e Cameral), esquema que prefigura o desenho geral de seu sistema teórico de Economia Política, posteriormente, desenvolvido em seu livro mais importante, 
Staatswirthschaft oder Systematische Abhandlung aller Oekonomischen und KameralWissenschaften, die zur Regierung eines Landes erfordert werden (Economia Política ou Tratado Sistemático de todas as Ciências Econômico-cameralistas necessárias ao Governo de um País, 1755) ${ }^{14}$ (CUNHA, 2013, p. 3-4; SMALL, 2001 [1909], p. 241; GUERRERO, 1986, p. 152; OSTERLOH, 1970, p. 20-21).

Visto que a concepção de economia política de Justi se configurou no âmago dos debates contemporâneos sobre comércio internacional, seu pensamento deve ser interpretado dentro da estrutura mais ampla da política européia, marcada pela competição entre potências imperiais. Suas propostas de reformas domésticas, por exemplo, resultam da constatação de que restrições ao poder político eram impostas pela necessidade de sucesso no comércio exterior. ${ }^{15}$ Nesse sentido, a política econômica exitosa é crucial à grandeza do Estado, ao passo que a política externa bem-sucedida e a ordem estatal proba e eficiente são necessárias à manutenção e ao aumento dos recursos econômicos. Cumpre frisar, todavia, que, apesar de perseguir a opulência do Estado, Justi não reconhece a primazia desta entidade sobre os indivíduos. Em vez disso, o Estado configura um complexo de instituições que se caracterizam pela existência e aplicação efetiva de normas geralmente vinculativas e permanentes, que indivíduos independentes estabelecem e mantêm para otimizar sua cooperação a fim de obter disso a maior renda real possível e poder satisfazer suas necessidades (BUSCH, 2010, p. 7-8).

$\mathrm{Na}$ verdade, Justi considerava a liberdade individual, a seguridade e a prosperidade material componentes da própria felicidade (Glückseligkeit). Nesse sentido, a função precípua do Estado consiste em garantir o bem-estar de seus cidadãos e, consequentemente, propiciar condições favoráveis à produção dos bens que os fazem felizes. Uma vez que as pessoas se

14 Justi anunciou no prefácio de seu Staatswissenschaft que mais quatro livros eram necessários para elaborar os subcampos da Economia Política: um sobre teoria política (Staatskunst); outro sobre política econômica doméstica (Policey-Wissenschaften); mais um sobre a teoria do comércio (Commercienwissenschaften); por fim, outro sobre economia (Oeconomie). Apenas dois dos livros anunciados, contudo, foram publicados: Natur und Wesen der Staaten (Natureza e essência dos Estados, 1760) foi a principal publicação de Justi em Staatskunst, enquanto Grundsätze der Policey-Wissenschaft (Princípios da Ciência Policial, 1756) foi o livro prometido em ciência da polícia. Outro livro importante sobre este assunto é Die Grundfeste zu der Macht und Glückseeligkeit der Staaten; oder ausführliche Vorstellung der gesamten Policey-Wissenschaft (Os fundamentos do poder e felicidade dos estados ou introdução completa a toda a ciência policial) (TRIBE, 2004, p. 9; NOKKALA, 2019, p. 33).

15Justi não subscreve o objetivo de maximizar o estoque de metais preciosos de uma nação, como muitas vezes foi atribuído às doutrinas mercantilistas. Suas ideias sobre o dinheiro aproximam-se da teoria monetária de David Hume, antecipando alguns dos aportes analíticos posteriormente desenvolvidos por Adam Smith em Wealth of Nations (Riqueza das Nações, 1776). Em seu entendimento, a circulação regular constitui a chave para o aumento da riqueza e do bem-estar. Com efeito, Justi argumenta que o Estado deve cuidar para que as reservas ociosas sejam mobilizadas para fins produtivos por meio de investimentos públicos em infraestrutura, construção de canais, portos, estradas etc. Decerto, ele acredita que sistema de crédito e bancário se afigura indispensável à promoção do desenvolvimento econômico e da prosperidade (CHALOUPEK, 2019, p. 5-6). 
empenham pela maior prosperidade material e o Estado existe unicamente para o bem e felicidade dos cidadãos, instituições políticas devem ser estabelecidas de modo a criar a maior renda per capita possível. Para Justi, portanto, legítimo é o Estado cujas instituições servem para criar liberdade, segurança e bem-estar (Wohlfahrt), o que não apenas sugere certa influência de John Locke (1632-1704), mas também coloca em evidência alguns dos aportes mais emblemáticos da teoria política liberal de corte smithiano. Ao delimitar a ação política, Justi intenciona mostrar que uma economia de mercado desregulamentada é superior a uma economia policial cameralística, não porque origina um produto interno maior, mas porque impõe menos restrições aos indivíduos, o que a torna incapaz de fornecer a cada cidadão uma maior quantidade de bens necessários a uma vida feliz ${ }^{16}$ (BUSH, 2010, p. 16-17).

Em seu Staatswissenchaft encontram-se, ademais, preceitos gerais sobre a profícua atividade de gestão pública. Sem dúvida, uma das teses mais importantes do livro e de todos os escritos de Justi sobre temas afins é a de que questões sociais são, em grande medida, problemas de administração pública (SMALL, 2001 [1909], p. 245; GUERRERO, 1986, p. 162). Em razão disso, tal como Seckendorff e a maioria dos escritores cameralistas da época, Justi tratou os problemas econômicos tendo em vista um governo que aceita as responsabilidades inerentes ao melhoramento das condições de vida e aperfeiçoamento moral dos súditos, obrigando-se não apenas a criar empregos e prover meios de subsistência para todos, mas também aprimorar os métodos e organização da produção para um fornecimento suficiente e satisfatório de matérias-primas e alimentos. Além disso, é de sua responsabilidade o embelezamento das cidades, o seguro contra incêndio, a educação, o saneamento etc. Novamente nota-se aqui que o Cameralismo não se prestava somente ao fortalecimento do Estado como finalidade única. Ao contrário, o propósito das Ciências Econômicas e Camerais envolvia favorecer a felicidade comum (Gemeinschaftliche Glückseligkeit), sendo que esta, por sua vez, comportava a conciliação do contentamento dos súditos com o triunfo do Estado, já que o bem de ambos estava concebido de modo idêntico ${ }^{17}$ (CUNHA, 2013, p. 7; SCHUMPETER, 2006, p. 167; JUSTI, 1755, p. 4-22).

$16 \mathrm{Na}$ base do pensamento político de Justi encontra-se a ideia de direito natural (Jus Naturale). De fato, ele era defensor de uma lei natural baseada na noção de indivíduos interessados em progredir em direção a uma sociedade comercial. O direito natural sobre o qual se funda sua teoria deriva dos instintos ou impulsos naturais (natürliche Triebe) de cada ser humano para desenvolver seus potenciais inatos com vistas a melhorar sua condição (BUSCH, 2010, p. 12).

17 Para Justi, a polícia desempenha um papel de suma importância na organização econômica, conquanto seu propósito não seja apenas aumentar o bem-estar material dos cidadãos, mas sim garantir a boa relação entre eles. Em outros termos, as leis policiais devem preservar o bem-estar de todas as famílias individuais, estabelecendo a mais exata conexão e concordância com o bem comum. Cabe à polícia, por exemplo, decidir sobre o tipo e 
Aliás, logo na primeira sessão de um opúsculo intitulado Kurze Geschichte des Finanzwesens und des Haushandels den allen Völkern (Breve História das formas financeiras e comerciais de todos povos), Justi, após extensiva investigação histórica, dedica-se ao tema da administração do patrimônio estatal, consoante a prática e êxito da polícia, do comércio e da economia, o que reforça a ideia de que as Ciências Camerais tinham sido divididas, mas não opostas ou dicotomizadas. Como a conjugação das atividades entre a polícia e a economia constitui o fundamento da ação governamental, essas atividades também favorecem a expansão das forças do Estado. Para Justi, assim como a Economia ou Haushaltungskunst ocupa-se de ensinar como os meios de vida das pessoas podem ser preservados, incrementados e razoavelmente aplicados, assim também sucede com as Ciências do Governo (Regierungswissenschaften) relativamente aos bens do Estado. Nesse caso, de acordo com Justi, as Ciências Econômicas equivaleriam à Ciência da Polícia na medida em que fossem observadas desde o ângulo da administração pública ${ }^{18}$ (TRIBE, 1988, p. 61; GUERRERO, 1986, p. 173; JUSTI, 1755, p. 6-20).

\begin{abstract}
A riqueza do Estado consiste não apenas de todos os tipos de bens móveis e imóveis que estão localizados nas fronteiras do país, quer pertençam aos súditos, quer sejam adquiridos diretamente pelo Estado, mas de todas as habilidades e aptidões das pessoas pertencentes à República; sim, a esse respeito, às pessoas mesmo devem ser imputados alguma consideração; e o uso geral de tal propriedade do Estado constitui precisamente o poder supremo. Todos os arranjos da autoridade suprema dependem também que ela faça das riquezas e poderes do Estado um uso sábio com vistas à realização da felicidade coletiva ${ }^{19}$ (JUSTI, 1755, p. 5, tradução nossa).
\end{abstract}

Após deixar a Áustria, Justi se estabeleceu, além da Dinamarca, em diversos Estados Alemães como Göttingen, Hamburg e Prússia, nos quais desenvolveu e expandiu sua concepção de Estado e Economia. A essas elucubrações, sucedeu-se vasta produção sobre as Ciências Camerais que exerceram significativa influência sobre as gerações posteriores. Após

extensão da produção agrícola e manufatureira, estando autorizada e obrigada a criar incentivos econômicos e instituir a disciplina e a ordem, zelando pela condição moral dos cidadãos a fim de encorajar-lhes a trabalhar diligentemente em um ambiente seguro (BUSCH, 16-17).

$18 \mathrm{O}$ termo Wirtschaft (Economia) aparece na literatura cameralista com o específico significado de que a atividade mais importante do Estado não é nem a troca nem a produção, mas a gestão e a alocação de recursos. Segundo Justi, a mais elevada prova de clarividência do governo se expressa no uso da riqueza e do poder estatal para a realização do bem-estar e felicidade dos súditos. Ele explicitamente afirma, antecipando Adam Müller e Friedrich List, que a riqueza (Vermögen) não se restringe a bens materiais, mas consiste de todas as capacidades e habilidades das pessoas, as quais devem ser desenvolvidas pelo Estado (LINDENFELD, 1997, p. 18-25).

19 "Das Vermögen des Staats besteht nicht nur in allen Arten von beweglichen und unbeweglichen Güthern, die in den Gränzen des Landes befindlich sind, und entweder den Unterthanen gehören oder dem Staate unmittelbar zustehen; sondern auch in allen Fähigkeiten und Geschicklichkeiten der zu der Republik gehörigen Personen; ja die Personen selbst müssen in gewissem Betracht darzu gerechnet werden; und der allgemeine Gebrauch dieses Vermögens des Staats machet eben die oberste Gewalt aus. Alle Anordnungen der obersten Gewalt kommen also darauf an, dass sie von dem Vermögen und den Kräften des Staats zu der Bewirkung der gemeinschaftlichen Glückseligkeit einen weisen Gebrauch machet” (JUSTI, 1755, p. 5). 
ter frutrado seus esforços para um cargo de professor universitário em Berlim, Justi foi finalmente nomeado administrador das minas (Berghauptmann), em 1765. Aqui novamente ele teve problemas, sendo acusado de desvio de fundos públicos, vindo a óbito na prisão, em 1771, antes de seu julgamento chegar ao fim.

\section{SONNENFELS E AS BASES SOCIOLÓGICAS DO ESTADO}

Joseph von Sonnenfels (1733-1817) é considerado o último grande pensador cameralista. Contemporâneo de Justi, sobreviveu a ele tempo suficiente para estender solidamente as Ciências Camerais até meados do século XIX. Sua obra mais importante, Grundsätze der Polizey, Handlung und Finanzwissenschaft (Princípios da Polícia, Comércio e Finanças, 1765), figura entre os livros mais vendidos da literatura econômica, estando em uso nas universidades austríacas até 1848. Embora a sorte de ambos autores tenha sido bastante diferente, eles convergem quanto ao propósito de formular estratégias de desenvolvimento com vistas, de um lado, aumentar o bem-estar da população, e de outro fortalecer o Estado. A obra de Sonnenfels, por exemplo, exprime um esforço para reconciliar as exigências de um Estado forte com as novas instituições criadas a partir da conjugação de diversos fatores culturais, políticos e econômicos, resultantes de eventos como a Revolução Francesa, a ocupação napoleônica e a Revolução Industrial ${ }^{20}$ (CHALOUPEK, 2019, p. 1-2; GUERRERO, 1846, p. 148; REINERT, 2007).

Proveniente de estirpe judaica recém-conversa ao catolicismo, Sonnenfels e sua família, em 1744, mudaram-se para Viena, onde seu pai, antigo rabino de Nikolsburg, foi nomeado professor de línguas orientais na Universidade e, logo depois, enobrecido em 1746. Após ingressar na Deutschmeisterregiment, Sonnenfels aplicou-se ao estudo da jurisprudência, tornando-se um dos mais esclarecidos intelectuais do círculo iluminista vienense, atuando, em seguida, na vida pública tanto no ofício de professor, quanto de administrador. Do mesmo modo que Seckendorff e Justi, assumiu Sonnenfels cargos públicos de grande relevância. Sua influência em vários assuntos, incluindo questões jurídica e econômica, baseava-se não apenas em seu status de conselheiro real e sua posição como

20 Após a dominação napoleônica e o Congresso de Viena, o vasto território que compreendia o antigo Sacro Império Germânico foi reunido em 33 Estados Alemães, com destaque para Áustria, Prússia, Saxônia, Baden, Württemberg, entre outros, que guardavam zelosamente seus direitos de autonomia, sua independência e, sobretudo, o controle das inúmeras aduanas nos rios e estradas que cortavam seus domínios. Ante o fortalecimento da Inglaterra como nação industrialmente desenvolvida e a reafirmação da Áustria e da Rússia como potências imperiais, ganha destaque o debate sobre a necessidade de supressão das barreiras política e econômica que até então dividiam os territórios germânicos, como forma factível de promover a superação do retardo técnico-industrial (OLIVEIRA, 2017, p. 186). 
docente, mas principalmente em numerosas publicações de artigos em jornais intelectuais (SCHUMPETER, 2006, p. 167; TRIBE, 1988, p. 78; CHALOUPEK, 2019, p. 9).

Em 1763, Sonnenfels foi nomeado professor de Ciência das Finanças e da Polícia (Finanz-und Policeywissenschaft), ao propor à imperatriz Maria Thereza a publicação periódica de suas pesquisas sobre ciências camerais. Dois anos depois, veio à luz um volumoso livro dividido em três tomos, cada um dos quais examinando as matérias de seu título, Grundsätze der Polizey, Handlung und Finanzwissenschaft. Neste livro, Sonnenfels sustenta a tese de que os objetivos primordiais do Estado podem ser divididos em quatro temas correlacionados, a saber, (i) a proteção externa, (ii) a segurança interna, (iii) a diversificação de ocupações produtivas e (iv) o incremento da renda. Essas quatro áreas compõem, em sua visão, o conteúdo da Ciência do Estado (Staatswissenschaft) e, ao mesmo tempo, as linhas de especialização que formam a Ciência Política, compreendendo as ciências da polícia, comércio e finanças. Enquanto a primeira apregoa princípios para o estabelecimento e manutenção da segurança interna e externa do Estado, a segunda se ocupa da ampliação benéfica do que a terra e a indústria produzem. Por fim, a última indica o modo como as receitas públicas devem ser aumentadas e administradas da maneira mais vantajosa (SONNENFELS, 1770, p. 29-30; TRIBE, 2006, p. 542; 1988, 78-84; LINDENFELD, 1997, p. 37).

O primeiro volume, o qual se incumbe da matéria do Estado e da polícia, soma mais de quinhentas páginas. Nele, a ideia de policia é enriquecida, ao ser integrada a ela a moralidade, a educação, a manutenção da segurança pública e privada, o equilíbrio adequado das instituições e dos poderes do Estado, a previdência etc. $\mathrm{O}$ propósito da política econômica, sob essa perspectiva, é prevenir a diminuição da oferta de bens mediante a regulamentação dos mercados. Segundo Sonnenfels, se a carência resultasse de um cultivo insuficiente, então isso seria um problema apenas para o agregado familiar como parte subordinada à ciência comercial. Caso a escassez resultasse, todavia, de preços muito altos ou de catástrofes, ela poderia ter sido evitada por meio do bom policiamento. Por outro lado, a fim de preservar a lisura e a integridade das práticas comerciais, o Estado deve intervir principalmente para eliminar incertezas quanto ao conteúdo, peso e composição das moedas. De fato, Justi e Sonnenfels concordam quanto à importância do dinheiro para efeito de geração de emprego, intercâmbio interno e externo de bens e serviço, assim como para o 
aumento da produção, população e bem-estar ${ }^{21}$ (CHALOUPEK, 2019, p. 10; GUERRERO, 1986, p. 144-147).

De um ponto de vista antropológico, Sonnenfels considera o homem um ser gregário, isto é, dotado de inclinação natural à vida em sociedade, alcançando sua máxima expressão social na figura do Estado, no interior do qual assume o caráter de cidadão, provido de espírito objetivo, unidade de vontade e propósito. Conquanto vislumbre na população uma preciosa fonte de riqueza, ele preconiza que seu crescimento se equipare ao montante de recursos disponíveis no Estado. De acordo com Omar Guerrero, a teoria demográfica constitui o cerne do argumento de Sonnenfels, de sorte que as quatro ciências do Estado estão

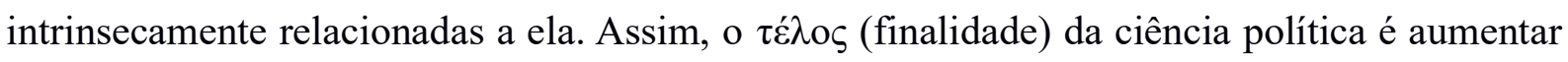
a população, pois seu crescimento favorece a segurança externa. A demografia compõe o objeto da ciência da polícia, pois nela reside um capital humano útil. A ciência do comércio se beneficia igualmente, pois disso origina-se mão-de-obra abundante para ser dedicada à indústria e à agricultura. Finalmente, o mesmo acontece com a ciência das finanças, uma vez que por seu intermédio recompõe-se as fileiras dos contribuintes. Em suma, o conhecimento da população é, em qualquer caso, essencial para todos os setores da administração pública (GUERRERO, 1986, p. 146-147; SMALL, 2001 [1909], p. 412).

A premissa do Estado está decerto presente em todo o edifício teórico de Sonnenfels. Ao conceber sociologicamente a natureza humana, ele caracteriza o Estado como a culminação do projeto de realização da objetividade da vida social. Por isso, a vontade coletiva (Gemeinschaftlichen Willen) é muito mais forte do que a do indivíduo. Na verdade, o pensamento de Sonnenfels pode ser compreendido como um modo de expressão da filosofia política alemã em sua forma orgânico-corporativista. Consoante esse ponto de vista, profusamente discutido na Rechtsphilosophie (Filosofia do Direito, 1820) de Hegel, o Estado é definido como concretude da idéia ética e expressão suprema de organização social, uma vez que nele todas as formas de alienação doméstica, conjugal e patriarcal são superadas como etapas rumo ao espírito objetivo. Em sua visão, nessa grande sociedade, seus membros

\footnotetext{
21 Sonnenfels acreditava que um montante suficiente de dinheiro efetivamente circulando garante que os fornecedores de bens encontrem proprietários de dinheiro dispostos a realizar trocas comerciais, fazendo com que os produtores se sintam mais inclinados a continuar suas atividades. Além disso, ele ressalta a gravidade dos riscos aos quais o fluxo receita-despesa está exposto em razão de uma possível retirada de dinheiro de circulação. Baseando-se na teoria quantitativa, Sonnenfels argumenta que uma modificação no nível de preços (Preiszahl) indica uma mudança na relação entre as quantidades de bens e meios de troca. Do mesmo modo, ele enfatiza a necessidade de mecanismos de regulamentação que assegurem o uso profícuo de uma maior quantidade de meios de pagamento por parte dos bancos de crédito (Leihbänke), de modo que se disponibilize capital para os negócios produtivos, nomeadamente, proprietários de terras e empresas industrial e comercial (CHALOUPEK, 2019, p. 11-12).
} 
adquirem novo nome, experimentam novos relacionamentos e tornam-se membros de um mesmo corpo moral, de sorte que o bem-estar das partes é baseado no bem-estar do todo, na mesma medida que o bem-estar coletivo (Gemeine Wohlfahrt) se fundamenta no bem-estar dos indivíduos $^{22}$ (HEGEL, 1973 [1818/1819], p. 322-324; 1969 [1830], p. 413).

Sonnenfels sugere que a necessidade de proteção, bem como a satisfação de anseios inerentes à manutenção da vida levaram os indivíduos socializarem-se uns com os outros, tornando menos penosa sua existência. O Estado, nesse sentido, funda as bases últimas dessa grande sociedade, em que os cidadãos unem suas forças para alcançar o bem comum. O efeito imediato disso é que os indivíduos assim reunidos são considerados pessoa moral e, consequentemente, tendo acima de si apenas a vontade comum de exigir o melhor para todos, suportam um único poder supremo, o qual consiste das forças próprias de todos os membros. Como bem observado por Albion Small, a teoria do Estado implícita na obra cameralista de Sonnenfels incumbe-se de conciliar as prerrogativas do governo centralizado às novas exigências do Século das Luzes. A solução por ele proposta busca harmonizar o interesse público ao privado (SONNENFELS, 1770, p. 18-33; SMALL, 2001 [1909], p. 409-412; GUERRERO, 1986, p.145).

Nota-se que Sonnenfels compôs a maior parte da produção cameralista usada no final do século XVIII. Entre 1760 e 1790, contam-se cerca de sessenta obras, introduções e traduções que podem ser classificadas como pertencentes ao corpo de ensino cameral. Destas, a maioria compartilhava de algum modo do paradigma proposto por Sonnenfels. Na verdade, sua influência manteve-se oficial não apenas dentro da monarquia austro-húngara, tendo se estendido para além das fronteiras austríacas, encontrando audiência inclusive nos Estados Alemães do Sul. Aliás, cumpre frisar que, devido ao seu vasto período de efetividade, o Cameralismo produziu efeitos de longo prazo, principalmente no que diz respeito à condução das políticas públicas e econômicas dos Estados Alemães. Com isso, ele fundou as bases últimas da Nationalökonomie, que viria a ser examinada a fundo e discutida de forma abrangente por Daniel Friedrich List (1789-1846), o qual, como burocrata e contemporâneo de Sonnenfels, formou-se sob a égide do Cameralismo ${ }^{23}$ (GUERRERO, 1985, p. 17; TRIBE, 2006, p. 542; 1988, 78-84; LINDENFELD, 1997, p. 37).

22 Como órgão vital de todo o organismo político, a burocracia era considerada parte integrante e, portanto, uma consequência necessária e legítima do desenvolvimento do Estado. No que diz respeito à promoção do bem-estar individual e público, Hegel atribuiu grande importância à administração pública, uma vez que ela, entendida como a consciência do Estado, implementaria o interesse público (ROSSER, 2010, p. 548).

23 List ingressou à administração pública, primeiro, como aprendiz em Blaubeuren, e depois, após passar no exame e exercer o ofício de assistente comissário de alfândega em Schelklingen, perto de Ulm, veio a ocupar, em seu vigésimo terceiro ano, um posto na burocracia de Tübingen (HIRST, 1909, p. 3). Posteriormente, ele 
Durante sua docência em Tübingen, List escreveu seu Gutachten über die Errichtung einer Staatswissenschaftlichen Fakultät (Parecer sobre o estabelecimento de uma Faculdade de Ciência Política, 1817), em que deixa evidente a influência da tradição cameralista na sua formação. Neste ensaio, porém, List sugere ser imperativo fundar as bases de uma nova Ciência do Estado, pois em seu ponto de vista esta disciplina, sobretudo no tocante à ciência da policia e das finanças, havia sido construída sobre alicerces inconsistentes, baseando-se, em grande medida, na experiência prática dos homens de ofício. List se queixava de que “todas as disciplinas da administração pública só pudessem ser aprendidas nas escrivaninhas e chancelarias" (LIST, 1850 [1817], p. 1-2). Em seu plano de curso, List destaca duas disciplinas essenciais, uma voltada à aprendizagem dos fundamentos do Estado (Staatsgelehrtheit) e a outra a ocupar-se da instrução atinente à Ciência do Direito (Rechtsgelehrtheit). ${ }^{24}$

Além disso, List propõe neste ensaio um primeiro esboço de sistematização das ciências econômicas, em que a Nationalökonomie (Economia Nacional) e a Privatökonomie (Economia Privada ou Individual) são apresentadas como disciplinas auxiliares, demonstrando que o bem-estar do todo resulta do bem-estar do indivíduo. Um segundo esquema encontra-se em sua Enziklopädie der Staatswissenschaften (Enciclopédia das Ciências Políticas, 1823). Neste manuscrito, List concebe a Economia Nacional como teoria das leis naturais de produção, distribuição e consumo de bens oriundos do comércio, indústria e agricultura. Trata-se, pois, da doutrina que ensina em que medida a influência do poder estatal pode ser benéfica ou prejudicial ao bem-estar econômico dos indivíduos, dos Estados e da humanidade, argumento que será retomado nos Outlines of Amercian Political Economy (1827) e, subsequentemente, no Système Naturel D'Économie Politique (1837). Em Das Nationale System der Politischen Ökonomie (Sistema Nacional de Economia Política, 1841) e outros escritos sobre a constituição das disciplinas econômicas, List apresenta uma concepção sistemática da economia ao dividi-la em: (i) Gesellschaftsökonomie (Économie Sociale,

ascendeu a um grau superior na hierarquia do Departamento da Chancelaria de Tübingen, ingressando, em seguida, no Ministério da Fazenda Real de Württemberg, onde assumiu um cargo como substituto na Secretaria da Fazenda nas cidades de Wiblingen e Ulm. Logo depois, List tornou-se assessor de finanças e contabilidade, e em 1816, foi nomeado primeiro professor de Administração e Política (Staatspraxis und Saatswissenschaft) na Universidade de Tübingen, Secretário do Ministério do Departamento de Governo Local e, subsequentemente, Inspetor-chefe geral de contas (DAASTØL, 2011, p. 21; LEVI-FAUR, 2012, p. 156).

24 A primeira subdivide-se, inter alia, em (i) História do Estado e Estatística (Staatsgeschichte und Statistik); Filosofia do Estado de Direito ou Ciência do Estado (Philosophisches Staatsrecht oder Staatswissenschaft); Jurisprudência e Administração (Gesetzkunde und Verwaltung); Teoria da Administração Pública (Staatsregierungslehre); Estado de Polícia (Staatspolizei). Por outro lado, a segunda disciplina trata da Filosofia do Direito (Rechtsphilosophie); História do Direito e o Espírito da Legislação (Rechtsgeschichte und Geist der Rechtsgesetzgebung); Prática Jurídica (Rechtspraxis) etc. (LIST, 1850 [1817], p. 6). 
conforme a nomeclatura já empregada no Sistema Natural), a qual abrange a Economia da Humanidade ou Cosmopolítica (Weltökonomie oder Ökonomie des gesamten menschlichen Geschlechts); Economia Política ou Nacional (Nationalökonomie oder Volkswirtschaftslehre); Economia Financiária Estatal (Staatsökonomie, Staatsfinanzwirtschaft, Finanzwissenschaft); e por fim (ii) Privatökonomie (Economia Privada ou do Indivíduo) (WENDLER, 1977, p. 110113).

\section{CONSIDERAÇÕES FINAIS}

$\mathrm{O}$ artigo buscou delinear o processo de implementação e desenvolvimento do Cameralismo, enquanto prática institucional típica dos principados alemães, considerando-se basicamente três recortes, ou seja, o período a que se sucedeu a Guerra dos Trinta Anos, o lapso correspondente ao Século das Luzes e o intervalo entre a Revolução Francesa e as guerras napoleônicas. Para tanto, foram abordados os pensamentos de três dos seus mais emblemáticos representantes, Seckendorff, Justi e Sonnenfels. Neles se verifica, sob diferentes perspectivas, um compromisso em fortalecer o Estado, tendo em conta a figura de um governo que aceita as responsabilidades inerentes ao melhoramento das condições de vida e aperfeiçoamento moral dos súditos. Detalhou-se, nesse sentido, a importância da ciência da polícia e da administração pública no que diz respeito, entre outras, à criação das condições propícias para o desenvolvimento, bem como à organização da produção para um fornecimento suficiente e satisfatório de matérias-primas e alimentos, como parte de um projeto de felicidade comum.

A partir de meados do século XVIII, observa-se um esforço sintético de combinar uma grande variedade de ideias contidas em inúmeros tratados, unificando-os em um sistema de ciência da política econômica e administrativa. As sínteses resultantes disso serviram como livros didáticos em universidades e outras instituições de ensino superior, onde as ciências camerais se estabeleceram firmemente no decorrer do século. As turbulências causadas pela Revolução Francesa e, sobretudo, pelas guerras napoleônicas minaram, entretanto, não apenas a estrutura social, política e econômica dos Estados Alemães, mas também implodiram o edifício do Cameralismo. No exato momento em que as Ciências Camerais tinham finalmente adquirido o estatuto de disciplina universitária, elas começaram a ser suplantadas por uma nova forma de raciocínio econômico. A partir de então, o ensino de Economia em universidades alemãs tornou-se província de uma nova doutrina, a qual enfatizava, entre outras coisas, a produtividade e as necessidades dos indivíduos como instâncias fundadoras da ordem econômica, mesmo que em prejuízo da atividade do governo sobre as populações dos 
Estados territoriais (SMALL, 2001 [1909], p. 167; LINDENFELD, 1997, p. 36-46; TRIBE, 1988, 91-92).

Nota-se que parte considerável das obrigações delegadas ao Estado por economistas alemães como Friedrich List já eram profusamente discutidas na doutrina cameralista. Isso permite entender, por exemplo, em que medida as ideias de Estado mínimo foram assimiladas nos territórios germânicos. Decerto, a ortodoxia liberal clássica teve maior aceitação em alguns Estados Alemães do norte, em que a presença da coroa inglesa era significativa, graças às suas possessões na Europa Central. O mesmo ocorreu nas cidades hanseáticas, em que os comerciantes pugnavam por menor intervenção do Estado na economia, e, sobretudo, na Prússia. Por outro lado, não se percebe o mesmo nível de assimilação da doutrina clássica nos domínios situados ao sul da Alemanha. Por fim, convém frisar que a ideia cameralista de Estado efetivo, capaz de estabelecer algumas poucas normas claras e gerais, que assegurassem relações econômicas equitativas, para garantir uma ordem competitiva isenta de privilégios de grupos individuais e interesses especiais fundamentou, a longo prazo, as bases da nationalökonomie, estendendo-se pelo Ordoliberalismo até chegar à Soziale Marktwirtschaft (Economia Social de Mercado), base das organizações econômica e política alemãs contemporâneas.

\section{REFERÊNCIAS BIBLIOGRÁFICAS}

ADAM, Ulrich. The Political Economy of J. H. G. Justi. Bern: Peter Lang, 2006.

ALEXANDRE, Antonio F. Economia e Polìtica em Hume. Philosophica, n. 11, p. 133-152, p. 1998.

BELL, John F. História do pensamento econômico. Rio de Janeiro: Zahar, 1961.

BILHIM, João; RAMOS, Ricardo; PEREIRA, Luis M. Paradigmas administrativos, ética e intervenção do Estado na economia: o caso de Portugal. Revista Digital de Derecho Administrativo. n. 14, p. 91-125, 2015.

BLAUG, Mark. Economic Theory in Retrospect. Cambridge: Cambridge University Press, 1985.
CUNHA, Alexandre M. Johann Heinrich Gottlob Von Justi (1717-1770) e o pensamento cameralista. Encontro Nacional de Economia ANPEC, p. 1-23, 2013.

BUSCH, Hans C. S. Die Kameralistik als politische Metaphysik. Aus der Schriftenreihe: Zuschnitte Diskussionspapiere der Zeppelin Universität, p. 1-18, 2010. Disponível em: https://www.zu.de/info-wAssets/zuschnitt/zu schnitt 07.pdf. Acesso em: 20/08/2020.

CHALOUPEK, Günther. Money and Banking in Austrian Cameralism - J. H. G. von Justi and Joseph von Sonnenfels. In: Annual Conference of the European Society for the History of Economic 
Thought (ESHET), 23., 2019, Lille, Anais eletrônicos: Money, Banks and Finance in Economic Thought. Lille, p. 1-22. Disponível em: http://www.chaloupek.eu/en/wpcontent/uploads/Money-and-Banking-inAustrian-Cameralism-2.pdf. Acesso em: 03/08/2020.

DAASTØL, Arno M. Friedrich List's Heart, Wit and Will: Mental Capital as the Productive Force of Progress. 2011, 583f. Tese (Doutorado em Economia) Staatswissenschaftliche Fakultät, Universität Erfurt, Erfurt. 2011.

EDELMAYER, Friedrich. Nuevas investigaciones sobre la historia del Sacro Império Romano Germânico (1519-1648). Cuadernos de Historia Moderna, n. 15, p. 171-189, 1994.

FORREST, A.; WILSON, P. H. (Org.). The bee and the Eagle: Napoleonic France and the End of the Holy Roman Empire, 1806. Basingstoke: Palgrave Macmillan, 2009.

GUERRERO, Omar. Los Espejos de los Príncipes Mulsumanes: Um programa de capacitación administrativa de alta jerarquía. Organo Informativo del Comite Mixto de Capacitación. n. 4, p. 514, 1982.

GUERRERO, Omar. Las Ciencias Camerales. Ensayos. Vol. 2, n. 6, p. 16-20, 1985.

GUERRERO, Omar. Las Ciencias de la Administración del Estado. México: Fontamata, 1986.

GODOY, Arilda S. Pesquisa Qualitativa. Tipos Fundamentais. Revista de Administração de Empresas. Vol. 35, n. 3. p. 20-29, 1995.

HEGEL, George F. W. Vorlesungen über Rechtsphilosophie 1818-1831. Der objektive Geist ; Naturrecht und
Staaswissenschaft nach der Vorlesungsnachschrift von C.G. Homeyer 1818/19 ; Zeitgenössische Rezensionen der Rechtsphilosophie: aus der Heidelberger Enzyklopädie 1817, mit Hegels Vorlesungsnotizen 18181819. Stuttgart: Frommann Holzboog, 1973.

HEGEL, Georg F. W. Enzyklopaedie der philosophischen Wissenschaften (1830). Felix Meiner Verlag: Hamburg, 1969.

HUME, David. Escritos econômicos. São Paulo: Abril Cultural, 1983 (Os Economistas). JACKSON, Michael. The eighteenth century antecedents of bureaucracy, the Cameralists. Management Decision. Vol. 43, n. 10, p. 1293-1303, 2005.

JUSTI, Johann G. H. Anweisung zu einer guten Deutschen Schreibart und allen in den Geschäfften und Rechtssachen vorfallenden schriftlichen Ausarbeitungen, zu welchen Ende allenthalben wohlausgearbeitet Proben und Beispiele beygefüget werden. Leipzig: Verlegts Bernard Christoph Breitkopf und Sohn. 1769.

JUSTI, Johann H. G. Staatswirthschaft oder systematische Abhandlung aller Oeconomischen und CameralWissenschaften, die zur Regierung eines Landes erfordert werden. Leipzig: Bernhard Christoph Breittropf Verlag, 1755 .

KLINGER, Andreas. Der Gothaer Fürstenstaat: Herrschaft, Konfession und Dynastie unter Herzog Ernst dem Frommen, Husum: Matthiesen Verlag, 2002.

KOCH, Peter. Pioniere des Versicherungsgedankens. Wiesbaden: Gabler Verlag, 1968. 
KRAUS, Hans C. Del Cameralismo a La Economía Nacional: La tradición alemana de las ciencias políticas hasta el comienzo del siglo XX. Historia 396, n. 1, p. 103$125,2011$.

LINDENFELD, David F. The partical imagination the German sciences of state in the nineteenth century. Chicago: University of Chicago Press, 1997.

LIST, Friedrich. Gutachten über die Errichtung einer Staatswirthschaftlichen Fakultät (1817). In: HAUESSER, Ludwig (ed). Friedrich List's gesammelte Schriften (Zweiter Theil). Band II, Stuttgard und Tübingen. J.G. Cotta'scher Verlag, p. 1-14, 1850.

LIST, Friedrich. Sistema Nacional de Economia Política (1841).São Paulo: Abril Cultural, 1983. (Os Economistas)

LLUCH, Ernest. El Cameralismo más allá del mundo germánico. Revista de Economia Aplicada. Vol 4, n. 10, p. 163175, 1996.

LÜTGE, Friedrich. Deutsche-Sozial- und Wirtschaftgeschichte. Heidelberg: Springer-Verlag, 1966.

MACK, Rüdiger. Christlich-toleranter Absolutismus: Veit Ludwig von Seeckendorff und sein Schüler Graf Friedrich Ernst zu Solms-Laubach. In: Mitteilung des Oberhessischen Geschichtsvereins Giessen Neuen Folge, n. 82, pp. 3-135, 1997.

NEU, Tim. Moralizing metaphors: Veit Ludwig von Seckendorff on parliamentary oratory. Parliaments, Estates \& Representation. Vol. 29, p. 85-101, 2009.

NOKKALA, Ere. From Natural Law to Political Economy: J.H.G. von Justi on State, Commerce and International Order. Münster: LIT Verlag Fresnostr., 2019.
OLIVEIRA, Flávio S. Bases do Nacionalismo Econômico em Friedrich List. Análise Econômica, Porto Alegre, ano 35, n. especial, p. 185-207, jul. 2017.

OSTERLOH, Karl-Heinz. Joseph von Sonnenfels und die oesterreichische Reformbewegung im Zeitalter ides aufgeklaerten Absolutismus: eine Studie in Zusammenhang von Kameralwissenschaft und Verwaltungspraxis. Matthiesen Verlag: Hamburg, 1970.

REINERT, Erik S. A Brief Introduction to Veit Ludwig Seckendorff (1626-1692). European Journal of Law and Economics. n. 19, p. 221-230, 2005.

REINERT, Erik S. Johann Heinrich Gottlob von Justi (1717- 1771): The Life and Times of an Economist Adventurer. In

KATTEL, Rainer (Ed.), The Visionary Realism of German Economics: From the Thirty Years' War to the Cold War. London: Anthem Press, p. 163-202, 2019.

REINERT, Sophus A. Another Grand Tour: Cameralism and Antiphysiocracy in Ba-den, Tuscany and Denmark-Norway. In: BACKHAUS, Jürgen G. (ed.) Physiocracy, Antiphysiocracy and Pfeiffer. New York: Springer, p. 39-69, 2011.

ROSSER, Christian. Woodrow Wilson's Administrative Thought and German Political Theory. Public Administration Review. Vol. 70, n. 4, p. 547-556, 2010.

SCHUMPETER, Joseph A. History of Economic Analysis. London: Routledge, 2006. SECKENDORFF, Ludwig V. Teutscher Fürsten-Staat. Sachsen: Theodor Wilhelm Ernst Verlag, 1754.

SECKENDORF, Veit L. von. Additiones oder Zugaben und Erleuterungen zu dem Tractat des Teutscher Fürsten- 
Stats, Frankfurt: Thomas Matthias Göken, 1665.

SMALL, Albion W. The Cameralists: The Pioneers of German Social Polity. Kitchener: Batoche Books, 2001.

SONNENFELS, Joseph v. Grundsätze der Polizey, Handlung und Finanzwissenschaft. Erster Theil. Dritte Auflage. Wien: Joseph Kurzböck, 1770.

TRIBE, Keith. Governing Economy: The Reformation of German Economic Discourse 1750-1840. Cambridge: Cambridge University Press, 1988.

TRIBE, Keith. Strategies of Economic Order: German Economic Discourse
(1750-1950). Cambridge: Cambridge University Press, 2004.

TRIBE, Keith. Cameralism and the sciences of the state. In: GOLDIE, Mark; WOKLER, Robert (ed) The Cambridge History of Eighteenth Century Political Thought. Cambridge: Cambridge University Press, p. 525-548, 2006.

WENDLER, Eugen.

Das betriebswirtschaftliche Gedankengebäude von Friedrich List Ein Beitrag zur Geschichte der Betriebswirtschaftslehre. (Rückenschild$\mathrm{Nr}$. 891). Inaugural-Dissertation zur Erlangung der Doktorwürde an der Eberhard-Karls-Universität zu Tübingen, Tübingen 1977.

\title{
CAMERALISM AND THE FOUNDATIONS OF STATE SCIENCE IN THE WRITING OF SECKENDORF, JUSTI AND SONNENFELS
}

\section{Flávio Oliveira}

How to cite this article: OLIVEIRA, Flávio. O Cameralismo e os fundamentos da Ciência do Estado nos escritos de Seckendorf, Justi e Sonnenfels. Revista de Ciências do Estado. Belo Horizonte: v. 6, n. 1, e25602. ISSN: 2525-8036.

\begin{abstract}
This paper highlights aspects of the political backdrop within which Cameralism was developed in order to assess Seckendorff, Justi and Sonnenfels' contributions to institutionalizing of State Science (Staatswissenschaft). Based on primary sources, as well as on the works of renowned scholars on the subject, the investigation outlines convergences between cameralist doctrine and the economic thought in vogue at the time. It is noted that though it was designed to advise the monarchical government on the solution of practical issues of public administration, economic policy and finance, Cameralism caused long-term effects, constituting the foundations upon which lie on one side the Nationalökonomie, and on the other the organic perspective inherent to the German state organization.
\end{abstract}

Keywords: Cameralism; State science; Seckendorff; Justi; Sonnenfels 